\title{
The relationship between diet, plasma lipid composition and aortic atherosis in rabbits
}

\author{
Bx J. H. MOORE AND D. L. WILLIAMS \\ National Institute for Research in Dairying, Shinfield, Reading \\ (Received ${ }_{12}$ February 1964-Accepted 7 April 1964)
}

In agreement with the observations of other investigators (e.g. Funch, Krogh \& Dam, 1960), Moore \& Kon (1963) and Moore \& Williams (1964) found that rabbits given for 9 or 10 months a diet containing $20 \%$ butterfat but no added cholesterol developed extensive aortic atherosis, whereas rabbits given for a similar period a diet containing $20 \%$ maize oil did not. The levels of plasma cholesterol of the rabbits given the $20 \%$ butterfat diet were four to five times higher than those of the rabbits given the $20 \%$ maize-oil diet. Thus, although the results with the animals given these two high-fat diets certainly appeared to lend support to the view that atheromatous degeneration is associated with high levels of cholesterol in the blood, the findings with groups of rabbits given various other diets indicated that the relationship between the level of cholesterol in the blood and atheromatous degeneration of the aorta, if indeed such a relationship exists, was by no means a simple one. For instance, it was discovered (Moore $\&$ Williams, 1964) that rabbits given a high-starch diet containing no added cholesterol and virtually no saturated fat developed aortic atherosis as severe as that in animals given the $20 \%$ butterfat diet, yet the plasma cholesterol levels of the rabbits given the high-starch diet were only moderately elevated. Moreover, rabbits given a diet containing 10\% butterfat and 10\% maize oil developed only slight aortic atherosis in spite of the fact that their level of plasma cholesterol was almost identical with that of rabbits given the high-starch diet. In general, therefore, it was evident that there was no direct relationship between the degree of hypercholesterolaemia and the extent of aortic atherosis in the experimental rabbit. On the other hand, it was conceivable that the incidence of atheromatous degeneration was related to the presence of abnormally high or low concentrations of certain other lipid components of the plasma. To investigate this possibility, the final blood samples taken from each of the experimental rabbits (Moore \& Williams, 1964) were analysed for the major lipid groups and an attempt was made to correlate the analytical results with the severity of the aortic lesions. The findings of this investigation are now reported.

\section{EXPERIMENTAL}

\section{Rabbits, diets and experimental procedure}

The experimental procedures will be summarized only briefly in the present paper since a detailed description of the diets and techniques employed in this study has been given in a previous communication (Moore \& Williams, 1964). The rabbits were those already used in the first study, with the exception of group 6 in Expt 2. 
Expt I. Forty male New Zealand white rabbits, 6 months of age at the beginning of the experiment, were divided into five groups of eight each. The animals were housed in individual cages and were given food and water ad lib. To 80 parts of a semi-purified basal diet (Moore \& Williams, I964) were added: for group I, 20 parts maize oil; for group 2, 24 parts butter (equivalent to 20 parts butterfat); for group 3, 20 parts butterfat; for group 4, 20 parts hydrogenated coconut oil; and for group 5, I part maize oil and $41 \cdot 9$ parts wheat starch. Since it was assumed that butterfat and maize oil contained 2.4 and $48.0 \%$ linoleic acid respectively, the diets given to the rabbits of groups 3 and 5 should have contained the same amount of linoleic acid per kcal gross energy. However, the assumed values for the linoleic acid content of these two dietary fats were found later to be incorrect and the necessary modifications were made in Expt 2. The rabbits were given the experimental diets for 30 weeks. At the end of this period a large sample of blood (approximately $50 \mathrm{ml}$ ) was taken from the marginal ear vein of each rabbit. All blood samples were collected in heparinized tubes. The rabbits were then killed by a blow on the hearl and as rapidly as possible thereafter the whole of the aorta was removed from each rabbit. The aortas were fixed in $4 \%(\mathrm{w} / \mathrm{v})$ formaldehyde in $0.9 \%(\mathrm{w} / \mathrm{v})$ sodium chloride saturated with calcium carbonate and were stained with Sudan IV $(0.05 \%$, w/v, in ethanol-acetone-water $35: 35: 30, v / v / v)$. The degree of atheromatous degeneration of the intimal surface was assessed by the method of Wigand (r959).

Expt 2. Eighty-four male New Zealand $\times$ Lop Ear rabbits, 4 months of age at the beginning of the experiment, were divided into six groups of fourteen each. The animals were again housed in individual cages and were given food and water ad lib. To 80 parts of the semi-purified basal diet were added: :or group I, 20 parts maize oil; for group 2, 20 parts butterfat; for group 3, 10 parts maize oil and 10 parts butterfat; for group 4, 0.47 parts maize oil and 43.1 parts wheat starch; and for group 5, 10.2 parts maize oil and $2 \mathrm{r} \cdot 6$ parts wheat starch. Gas chromatographic analysis had shown that the percentage of linoleic acid in the maize oil and butterfat used in these experiments was $53^{\circ} \circ$ and $\mathrm{I} \cdot 26$ respectively. Therefore the diets given to the rabbits of groups 2 and 4 contained the same amounts of linoleis acid per kcal gross energy; so did the diets given to the rabbits of groups 3 and 5. The animals in group 6 were given an ordinary commercial rabbit diet. The experimental and commercial diets were given to the rabbits for a period of 36 weeks after which a large sample of blood was taken from the marginal ear vein of each rabbit. The rabbits were then killed and the aortas were removed and treated as in Expt I. The deg:ee of atheromatous degeneration of the intimal surface was determined as described by Moore \& Williams (1964).

\section{Analytical procedure}

Solvents. The solvents used in the extraction, fractionation and analytical procedures were as described by Moore \& Doran (1962).

Extraction of lipids. The lipids were extracted from the plasma samples by an adaptation of the method of Folch, Lees \& Stanley (1957) described by Nelson \& Freeman (1959). In addition, all lipid extracts were taken to dryness under reduced pressure in a rotary film evaporator connected to a supply of nitrogen. 'The dry 
residues were rapidly taken up in chloroform, filtered and then stored in chloroformmethanol $(2: \mathrm{I}, \mathrm{v} / \mathrm{v})$ in a cold room.

Fractionation of lipids. The plasma lipids were fractionated on columns of silicic acid by an adaptation of the method of Barron \& Hanahan (1958). The essential details of this adaptation have been given by Moore \& Doran (1962) but in the present work the columns consisted of only $\mathrm{I} g$ of silicic acid. The silicic acid (100 mesh; AR; Mallinckrodt Chemical Works) was activated and washed as described previously (Moore \& Doran, 1962). The columns were prepared from a suspension of the silicic acid in hexane and measured $70 \mathrm{~mm} \times 6 \mathrm{~mm}$ when packed under nitrogen at a pressure of $10 \mathrm{lb} / \mathrm{in}^{2}$. The chromatographic separations were carried out in an

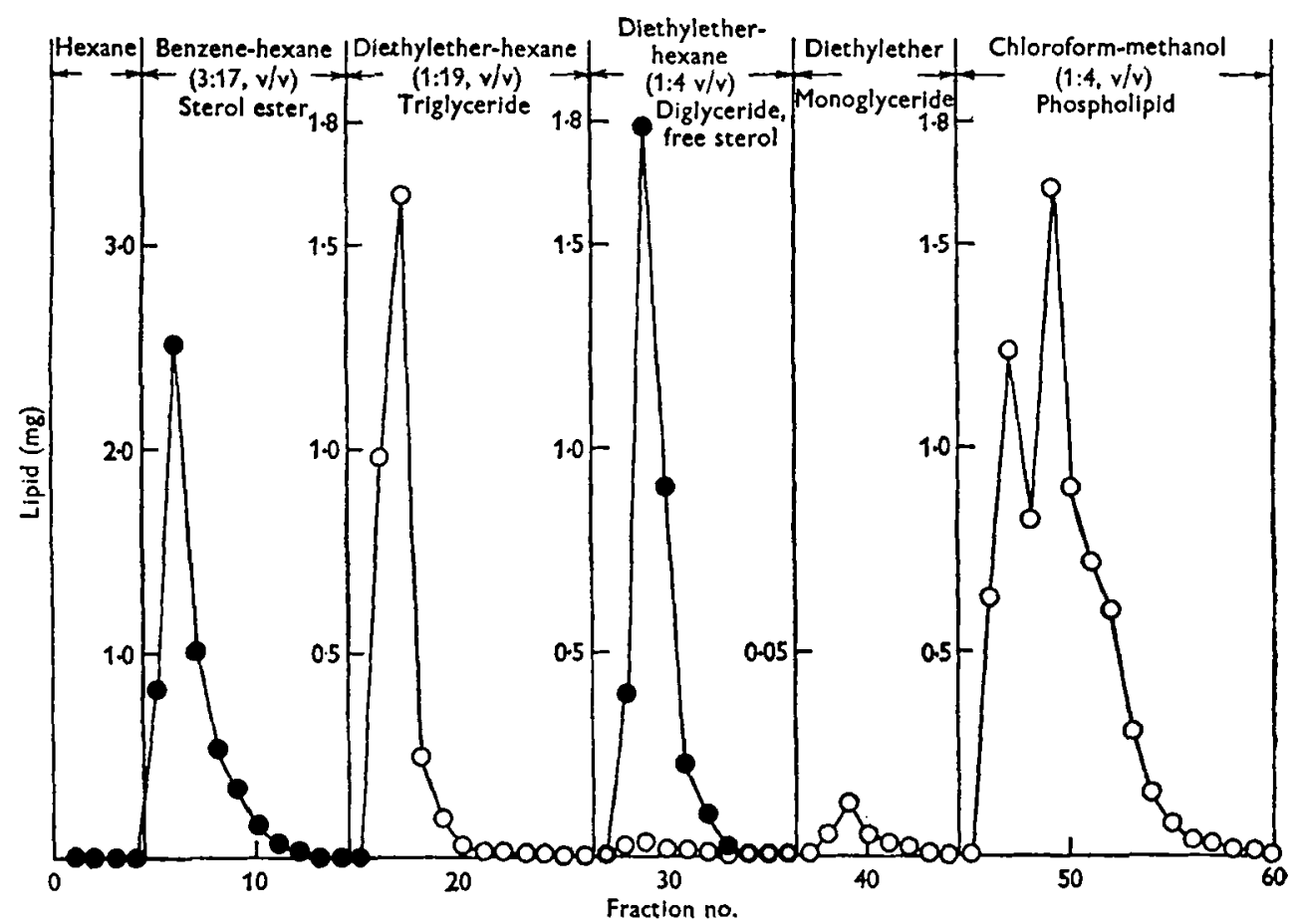

Fig. 1. Chromatography of plasma lipids of a rabbit given the $20 \%$ butterfat diet (group 2, Expt 2) on a $1 \mathrm{~g}$ column of silicic acid. The column eluate was collected in $5 \mathrm{ml}$ fractions. Column load: $19.6 \mathrm{mg}$ of lipid. $\bullet$, Liebermann-Burchard-reacting lipids; $\odot$, glycerolcontaining lipids.

apparatus similar to that devised by Lis, Tinoco \& Okey (1961) with the exception that a sintered-glass plate was fused to the base of each column and that all connexions were of standard ground-glass joints. Samples of about $20 \mathrm{mg}$ lipid dissolved in small volumes of hexane were placed on the columns and the various fractions were eluted under a positive pressure of nitrogen at $10 \mathrm{lb} / \mathrm{in}^{2}$. As an example of the efficiency of separation that may be obtained with these micro-columns the chromatography of the plasma lipids of a rabbit given the diet containing $20 \%$ butterfat (group 2, Expt 2) is illustrated in Fig. I. Recovery of lipid from the columns was between 97 and $100 \%$. In view of the fact that the diglyceride and monoglyceride 
fractions accounted for only about 2.8 and $0.8 \%$ respectively of the total plasma glyceride (see Fig. I) it did not seem profitable as a routine procedure to analyse the three glyceride fractions separately. The fractions containing triglyceride, diglyceride with free cholesterol, and monoglyceride (see Fig. I) were therefore combined before the determination of glyceride glycerol and cholesterol. To prepare phospholipid-free extracts necessary for the titration of unesterified fatty acids, lipid samples in small volumes of chloroform were placed on I $g$ columns of silicic acid and were then eluted with an excess of chloroform. Under these conditions the phospholipids remained on the column but the other lipids, including the unesterified fatty acids, passed into the eluate. The efficiency of the separations of the lipid fractions on the columns of silicic acid was continually checked by chromatography of portions of each fraction on thin layer chromatoplates of Silica Gel G (Mangold, I96I) with a solvent system of light petroleum (boiling range $40-60^{\circ}$ )-diethyl ether $(90: 10, \mathrm{v} / \mathrm{v})$.

Methods of analysis. The total lipid contents of the extracts were determined gravimetrically. The various fractions obtained from the columns of silicic acid were analysed for glyceride glycerol, cholesterol, phosphorus and unesterified fatty acids by the methods described previously (Moore, 1962; Moore \& Doran, 1962; Moore \& Williams, 1963). Weights of cholesterol ester and unesterified fatty acids were calculated in terms of oleic acid. No correction was made for the presence of small amounts of di- and mono-glycerides and the total glyceride glycerol values were arbitrarily converted into weights of triolein. For convenience, this fraction is referred to as the triglyceride fraction throughout the rernainder of this paper. Weights of phospholipid were obtained by multiplying the phosphorus values by 25 (Wittcoff, I95 I).

Statistical analysis. From a preliminary examination of the results it was evident that the standard deviation between animals within a diet group tended to be proportional to the diet group mean. Consequently all observations were transformed to logarithms in order to reduce heterogeneity among the within-group variances. The tests of significance summarized in Tables $I$ and 2 refer to differences between mean logarithmic values of each diet group. These mean logarithmic values are presented in Tables $I$ and 2 by their antilogarithms which are the geometric means of each diet. Arithmetic means of the untransformed values are also given; they agree roughly with the geometric means which are invariably smaller. The tests of significance are based on the multiple-range test (Duncan, 1955) as modified for unequal numbers of replications (Kramer, 1956). The $1 \%$ level of significance was accepted as indicating a real biological difference.

\section{RESULTS AND DISCUSSION}

\section{The effect of diet on plasma lipid composition}

Expt I (Table I). The levels of the various lipid cornponents in the plasma of the rabbits given the diet containing hydrogenated coconul: oil (group 4) were far greater than the corresponding levels in the plasma of the rabbits in groups $1,2,3$ and 5 . It seems likely, however, that these extremely high levels of lipid were present in the 
'Table I. Expt I. Concentration of lipid components $(\mathrm{mg} / 100 \mathrm{ml})$ in the plasma of rabbits on the various dietary treatments. Ranking of means and significance of differences by the multiple-range test (Duncan, 1955; Kramer, 1956)

(The mean values differ significantly $(P=0.01)$ except when they share a common underlining)

Total lipid

Group no....

Arithmetic mean

Geometric mean

Mean log

Group no....

Arithmetic mean

Geometric mean

Mean log

Group no....

Arithmetic mean

Geometric mean

Mean $\log$

Group no....

Arithmetic mean

Geometric mean

Mean $\log$

Group no....

Arithmetic mean

Geometric mean

Mean log

Group no....

Arithmetic mean

Geometric mean

Mean $\log$

Group no....

Arithmetic mean

Geometric mean

Mean log

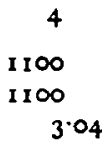

$3 \cdot 04$

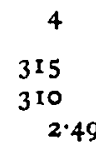

$2 \cdot 49$

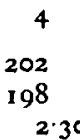

2.30
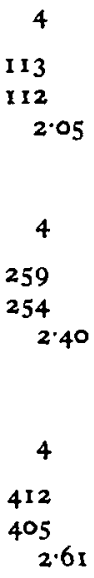

\begin{tabular}{cc}
2 & 3 \\
168 & 161 \\
162 & 160 \\
$2 \cdot 21$ & $2 \cdot 20$ \\
\hline
\end{tabular}

4
$48 \cdot 4$
$44 \cdot 9$
$1 \cdot 65$

\begin{tabular}{rc}
3 & 2 \\
$46 \mathrm{r}$ & 466 \\
459 & 454 \\
$\mathbf{2} \cdot 66$ & $2 \cdot 66$ \\
\hline
\end{tabular}

\begin{tabular}{rr}
2 & 3 \\
154 & 149 \\
150 & 148 \\
$2 \cdot 18$ & $2 \cdot 17$ \\
\hline
\end{tabular}

\begin{tabular}{cc}
2 & 3 \\
$77^{\cdot 1}$ & $74 \cdot 0$ \\
$75^{\cdot 1}$ & $72 \cdot 9$ \\
$1 \cdot 88$ & $1 \cdot 86$ \\
\hline
\end{tabular}

Triglyceride
Unesterified fattv acids

\begin{tabular}{cccc}
3 & 2 & 1 & 5 \\
$21 \cdot 2$ & 15.4 & $14 \cdot 0$ & $12 \cdot 9$ \\
$20 \cdot 7$ & $14 \cdot 7$ & $13 \cdot 7$ & $12 \cdot 9$ \\
$1 \cdot 31$ & $1 \cdot 17$ & $1 \cdot 14$ & $1 \cdot 11$ \\
\hline
\end{tabular}

$\begin{array}{cc}5 & 1 \\ 299 & 216 \\ 294 & 213 \\ 2 \cdot 47 & 2 \cdot 32\end{array}$

Total cholesterol

$\begin{array}{cc}5 & 1 \\ 95 \cdot 0 & 44 \cdot 4 \\ 92 \cdot 0 & 43 \cdot 9 \\ 1 \cdot 96 & 1 \cdot 64\end{array}$

Free cholesterol

$$
5
$$

$\boldsymbol{I}$

$19 \cdot 0$

$\begin{array}{ll}41 \cdot 7 & 19 \cdot 0 \\ 40 \cdot 7 & 18 \cdot 7\end{array}$

$1 \cdot 61 \quad 1.27$

Esterified cholesterol

Phospholipid

Error

variance

(28 df)

(log units)

0.00713

0.00827

0.00937

\begin{tabular}{ccccc}
2 & 3 & 5 & 1 & \\
$76 \cdot 8$ & $74 \cdot 7$ & $53 \cdot 5$ & $25 \cdot 5$ & \\
74.8 & $73 \cdot 9$ & 51.3 & $25 \cdot 1$ & \\
1.87 & 1.87 & 1.71 & 1.40 & 0.00977 \\
\hline
\end{tabular}

\begin{tabular}{ccccc}
3 & 2 & 5 & 1 & \\
$78 \cdot 9$ & $73 \cdot 7$ & $64 \cdot 7$ & $48 \cdot 5$ & \\
$77 \cdot 2$ & 70.4 & $63 \cdot 6$ & $47 \cdot 1$ & \\
1.89 & $1 \cdot 85$ & $1 \cdot 80$ & $1 \cdot 67$ & 0.01214 \\
\hline
\end{tabular}

Group I ( $20 \%$ maize-oil diet), group 2 ( $24 \%$ butter diet), group 3 ( $20 \%$ butterfat diet), group 4 (hydrogenated coconut-oil diet), group 5 (low-fat, high-starch diet).

Certain of the animals died during the experiment. The numbers at the end of the experiment were: group $x, 8$; group2, 7 ; group 3,6 ; group 4,6 ; group 5,6 . 
Table 2. Expt 2. Concentration of lipid components ( $\mathrm{mg} / \mathrm{100} \mathrm{ml}$ ) in the plasma of rabbits on the various dietary treatments. Ranking of means and significance of differences by the multiple-range test (Duncan, 1955; Kramer, 1956)

(The mean values differ significantly $(P=0.01)$ except when they share a common underlining)

\begin{tabular}{|c|c|c|c|c|c|c|c|}
\hline \multirow[b]{2}{*}{ Group no... } & \multicolumn{6}{|c|}{ 'l'otal lipid } & \multirow[t]{2}{*}{$\begin{array}{c}\text { Error } \\
\text { variance } \\
(66 \mathrm{df}) \\
\text { (log units) }\end{array}$} \\
\hline & 2 & 3 & 4 & 5 & 6 & I & \\
\hline $\begin{array}{l}\text { Arithmetic mean } \\
\text { Geometric mean } \\
\text { Mean log }\end{array}$ & $\begin{array}{l}45 I \\
445 \\
2 \cdot 65\end{array}$ & $\begin{array}{r}322 \\
320 \\
2 \cdot 50 \\
\end{array}$ & $\begin{array}{l}262 \\
260 \\
2 \cdot 41 \\
\end{array}$ & $\begin{array}{l}207 \\
202 \\
2 \times 31 \\
\end{array}$ & $\begin{array}{r}204 \\
201 \\
2 \cdot 30 \\
\end{array}$ & $\begin{array}{r}204 \\
193 \\
2 \cdot 29 \\
\end{array}$ & $0.0089 r$ \\
\hline Mean $\log$ & \multicolumn{6}{|c|}{ Total cholesterol } & \\
\hline Group no.... & 2 & 4 & 3 & 5 & 6 & $\mathbf{I}$ & \\
\hline $\begin{array}{l}\text { Arithmetic mean } \\
\text { Geometric mean } \\
\text { Mean log }\end{array}$ & $\begin{array}{l}151 \\
148 \\
2 \cdot 17\end{array}$ & $\begin{array}{r}85 \cdot 4 \\
83 \cdot 0 \\
1 \cdot 92 \\
\end{array}$ & $\begin{array}{r}83 \cdot 8 \\
82 \cdot 6 \\
1 \cdot 92 \\
\end{array}$ & $\begin{array}{r}55 \cdot 7 \\
54 \cdot 5 \\
r \cdot 74 \\
\end{array}$ & $\begin{array}{r}50 \cdot 5 \\
48 \cdot 2 \\
1 \cdot 68 \\
\end{array}$ & $\begin{array}{c}44 \cdot 9 \\
39 \cdot 9 \\
1 \cdot 60 \\
\end{array}$ & 0.01745 \\
\hline Mean log & \multicolumn{6}{|c|}{ Free cholesterol } & \\
\hline Group no.... & 2 & 3 & 4 & 5 & 6 & $\mathbf{I}$ & \\
\hline \multirow[t]{2}{*}{$\begin{array}{l}\text { Arithmetic mean } \\
\text { Geometric mean } \\
\text { Mean log }\end{array}$} & $\begin{array}{c}76 \cdot 0 \\
74 \cdot 4 \\
1 \cdot 87\end{array}$ & $\begin{array}{r}41.7 \\
39 \cdot 8 \\
1.60 \\
\end{array}$ & $\begin{array}{r}37 \cdot 0 \\
34 \cdot 9 \\
1 \cdot 54 \\
\end{array}$ & $\begin{array}{r}25 \cdot 4 \\
24 \cdot 2 \\
1 \cdot 38 \\
\end{array}$ & $\begin{array}{l}21 \cdot 6 \\
19 \cdot 9 \\
1 \cdot 30\end{array}$ & $\begin{array}{l}22 \cdot 0 \\
18 \cdot 7 \\
1 \cdot 27\end{array}$ & 0.02991 \\
\hline & \multicolumn{6}{|c|}{ Esterified cholesterol } & \\
\hline Group no.... & 2 & 4 & 3 & 5 & 6 & $\mathbf{I}$ & \\
\hline \multirow[t]{2}{*}{$\begin{array}{l}\text { Arithmetic mean } \\
\text { Geometric mean } \\
\text { Mean log }\end{array}$} & $\begin{array}{l}75 \cdot 0 \\
73 \cdot 7 \\
1.87\end{array}$ & $\begin{array}{r}48 \cdot 4 \\
46 \cdot 6 \\
r \cdot 67 \\
\end{array}$ & $\begin{array}{l}42 \cdot 0 \\
41 \cdot 3 \\
1 \cdot 62 \\
\end{array}$ & $\begin{array}{r}30.3 \\
29.8 \\
1.47 \\
\end{array}$ & $\begin{array}{r}28 \cdot 8 \\
27 \cdot 5 \\
1 \cdot 44 \\
\end{array}$ & $\begin{array}{r}22 \cdot 9 \\
20 \cdot 5 \\
I \cdot 31\end{array}$ & 0.01735 \\
\hline & \multicolumn{6}{|c|}{ Triglyceride } & \\
\hline Group no.... & 2 & 3 & 4 & 6 & 5 & I & \\
\hline \multirow[t]{2}{*}{$\begin{array}{l}\text { Arithmetic mean } \\
\text { Geometric mean } \\
\text { Mean log }\end{array}$} & $\begin{array}{r}69.5 \\
64.6 \\
1 \cdot 81 \\
\end{array}$ & $\begin{array}{r}6 r \cdot 5 \\
60 \cdot 2 \\
I \cdot 78 \\
\end{array}$ & $\begin{array}{c}6 r \cdot 1 \\
56 \cdot 3 \\
1 \cdot 75 \\
\end{array}$ & $\begin{array}{l}50 \cdot 3 \\
46 \cdot 3 \\
r \cdot 67 \\
\end{array}$ & $\begin{array}{r}48 \cdot 5 \\
46 \cdot 1 \\
1 \cdot 66 \\
\end{array}$ & $\begin{array}{r}48 \cdot 3 \\
42 \cdot 7 \\
1 \cdot 63 \\
\end{array}$ & 0.03072 \\
\hline & \multicolumn{5}{|c|}{ Phospholipid } & & \\
\hline Group no.... & 2 & 3 & I & 5 & 4 & 6 & \\
\hline \multirow[t]{2}{*}{$\begin{array}{l}\text { Arithmetic mean } \\
\text { Geometric mean } \\
\text { Mean log }\end{array}$} & $\begin{array}{r}163 \\
160 \\
2 \cdot 20 \\
\end{array}$ & $\begin{array}{r}132 \\
130 \\
2 \cdot 11 \\
\end{array}$ & $\begin{array}{l}83 \cdot 2 \\
79 \cdot 0 \\
1 \cdot 90 \\
\end{array}$ & $\begin{array}{c}71 \cdot 9 \\
70.6 \\
1.85 \\
\end{array}$ & $\begin{array}{c}72 \cdot 1 \\
69 \cdot 9 \\
1 \cdot 84 \\
\end{array}$ & $\begin{array}{r}67 \cdot 3 \\
65 \cdot 8 \\
1 \cdot 82 \\
\end{array}$ & 0.01115 \\
\hline & \multicolumn{6}{|c|}{ Unesterified fatty acicls } & \\
\hline Group no.... & 2 & 3 & 6 & $I$ & 5 & 4 & \\
\hline $\begin{array}{l}\text { Arithmetic mean } \\
\text { Geometric mean } \\
\text { Mean log }\end{array}$ & $\begin{array}{l}17 \cdot 3 \\
16 \cdot 0 \\
I \cdot 20 \\
\end{array}$ & $\begin{array}{l}16 \cdot 8 \\
15.9 \\
1.20\end{array}$ & $\begin{array}{r}15 \cdot 7 \\
13 \cdot 6 \\
1 \cdot 13 \\
\end{array}$ & $\begin{array}{l}11 \cdot 6 \\
10 \cdot 8 \\
1.03\end{array}$ & $\begin{array}{c}10.7 \\
9.19 \\
0.96\end{array}$ & $\begin{array}{l}10.1 \\
7.87 \\
0.90\end{array}$ & 0.05439 \\
\hline
\end{tabular}

Group I (20\% maize oil diet), group 2 (20\% butterfat diet), group 3 (10\% maize-oil, 10\% butterfat diet), group 4 (low-fat, high-starch diet), group 5 (10\% maize-sil, starch diet), group 6 (commercial diet).

Certain of the animals died during the experiment. The numbers at the end of the experiment were: group 1,12 ; group 2,13 ; group 3,13 ; group 4,$12 ;$ group 5 , 10 ; group 6,12 
plasma of the rabbits in group 4 only during the last ro weeks of the feeding period (Moore \& Williams, I964). There was no significant difference between the concentrations of the various plasma lipids in the rabbits given the diet containing butter (group 2) and those in the rabbits given the diet containing butterfat (group 3). Although the levels of total lipid, phospholipid and free and esterified cholesterol in the plasma of the rabbits in groups 2 and 3 were significantly higher than the levels of these lipids in the plasma of the rabbits given the high-starch diet (group 5), there were no significant differences in the levels of triglyceride in the plasma of the rabbits in groups 2,3 and 5 and there was no significant difference in the levels of unesterified fatty acids in the plasma of the rabbits in groups 2 and 5 . The concentration of total lipid in the plasma of the rabbits given the high-starch diet (group 5) was significantly higher than the corresponding value for the rabbits given the diet containing $20 \%$ maize oil (group I) but this difference seemed to be due mainly to the higher levels of free and esterified cholesterol in the plasma of the rabbits in group 5. The levels of triglyceride, phospholipid and unesterified fatty acids in the plasma of the rabbits given the high-starch diet (group 5) did not differ significantly from the levels of these lipids in the plasma of the rabbits in group $\mathrm{I}$.

Expt 2 (Table 2). The concentrations of the various lipid fractions in the plasma of the rabbits in groups I (20\% maize-oil diet), 5 (10\% maize-oil-starch diet) and 6 (commercial diet) were all very similar, although in group 5 the concentration of esterified cholesterol in the plasma was significantly higher than that in the plasma of the rabbits in group r. The highest levels of total lipid and free and esterified cholesterol in the plasma were observed in the rabbits of group 2 given the diet containing $20 \%$ butterfat. Nevertheless, the levels of phospholipid, triglyceride and unesterified fatty acids in the plasma of the rabbits in group 2 were not significantly different from the corresponding levels in the plasma of the rabbits in group 3 given the diet containing $10 \%$ maize oil and $10 \%$ butterfat. It should be noted that although the concentration of cholesterol in the plasma was the same in the rabbits of groups 3 and 4 , the concentration of plasma phospholipid in the rabbits of group 3 was about twice that found in the rabbits of group 4. The level of triglyceride in the plasma was not influenced significantly by the various dietary treatments. The results obtained for the rabbits given the $20 \%$ maize-oil diet, the $20 \%$ butterfat diet and the high-starch diet in Expt 2 (Table 2) were very similar to those obtained for the rabbits given the same diets in Expt I (Table I).

Thus these findings on the effect of diet on the levels of the various plasma lipids in the rabbits of Expts $I$ and 2 are in general agreement with the findings of Wigand (1959) for the serum lipids of rabbits that had been given diets containing $8 \%$ maize oil, $8 \%$ butterfat or $8 \%$ hydrogenated coconut oil for periods of 15 or 18 weeks. However, in the experiments of Wigand (1959) the absolute levels of lipid in the serum of the rabbits given diets containing $8 \%$ butterfat or $8 \%$ hydrogenated coconut oil were considerably higher than the levels of lipid found by us in the plasma of rabbits given diets containing $20 \%$ butterfat or $20 \%$ hydrogenated coconut oil. As discussed previously (Moore \& Williams, r 964 ) an explanation of this disparity may be found in the differences in the composition of the basal diets used by Wigand (1959) and ourselves. 


\section{Relationship between plasma lipid composition and the degree of aortic atherosis}

Considering the possible connexions between certain abnormalities in the composition of blood lipids and cardiovascular disease in man it would seem appropriate now to examine in some detail the relationship between the concentration of the various lipid components in the plasma and the degree of aortic atherosis in the individual rabbits of Expt 2, the experiment in which the severity of the aortic lesions was quantitatively assessed in arbitrary units from 0 to 80 (Moore \& Williams, 1964). The mean degrees of aortic atherosis for the rabbits in the six groups of Expt 2 are given in Table 3. In Expt I the aortas were graded merely intc the four categories described by Wigand (1959) and Moore \& Williams (1964).

\section{Table 3. Expt 2. Degrees of severity* of the atheromatous lesions in the aortas of the experimental rabbits}

(Mean values with their standard errors)

\begin{tabular}{|c|c|c|c|c|c|}
\hline $\begin{array}{c}\text { Group I } \\
\text { (20\% maize- } \\
\text { oil diet) }\end{array}$ & $\begin{array}{c}\text { Group 2 } \\
\text { (20\% butter- } \\
\text { fat diet) }\end{array}$ & $\begin{array}{c}\text { Group } 3 \\
\text { (10 \% maize-oil, } \\
\text { 10\% butterfat } \\
\text { diet) }\end{array}$ & $\begin{array}{c}\text { Group 4 } \\
\text { (low-fat, } \\
\text { high-starch } \\
\text { diet) }\end{array}$ & $\begin{array}{l}\text { Group } 5 \\
\text { (10\% maize- } \\
\text { oil, starch } \\
\text { diet) }\end{array}$ & $\begin{array}{c}\text { Group } 6 \\
\text { (commercial } \\
\text { diet) }\end{array}$ \\
\hline $1.61 \pm 0.8 \dagger$ & $18 \cdot 9 \pm 5 \cdot 3$ & $2.0 \pm 0.6 \dagger$ & $22 \cdot 9 \pm 7 \cdot 5$ & $1.32 \pm 0.6 \uparrow$ & $1.65 \pm 0.46$ \\
\hline
\end{tabular}

Total lipid. Before dealing specifically with individual plasma lipids, it is perhaps well to consider the relationship between the degree of aortic atherosis and the concentration of total lipid in the plasma of the rabbits in Expt 2. As may be seen from Fig. 2, there was no simple correlation, but it would seem that, although severe atherosis was rarely observed when the total lipid levels were less than about $230 \mathrm{mg}$ / $100 \mathrm{ml}$ plasma, extremely high levels of total lipid in the plasma were frequently associated with little or no atherosis. It should also be pointed out that there was no apparent correlation between the severity of atherosis and the degree of visible lipaemia of the plasmas. For instance, in both experiments, plasma exhibiting a pronounced lipaemia was invariably obtained from the rabbits given the diets containing $20 \%$ butterfat, but little or no lipaemia was observed in the plasma obtained from the rabbits given the high-starch diets.

Cholesterol. During the last 30 years or so there has been intensive discussion on the possible existence of a relationship between hypercholesterolaemia and cardiovascular disease in man and the subject has been reviewed in detail by many authorities (e.g. Hirsch \& Weinhouse, 1943; Kritchevsky 1958; Kinsell, 1963). Although the weight of opinion is in favour of the view that hypercholesterolaemia predisposes to atherosclerosis in man, there is by no means complete agreement. For instance it is extremely difficult to disregard the work of Lande \& Sperry (r936) who were unable to find any correlation between blood cholesterol level and the degree of atherosclerosis or the amount of lipid deposited in the aortas of a large number of persons who had 
met violent deaths. As so appositely pointed out by Kritchevsky (1958) 'the literature relating to atherosclerosis is so extensive that it is possible to find conflicting views on practically every aspect of the disease'.

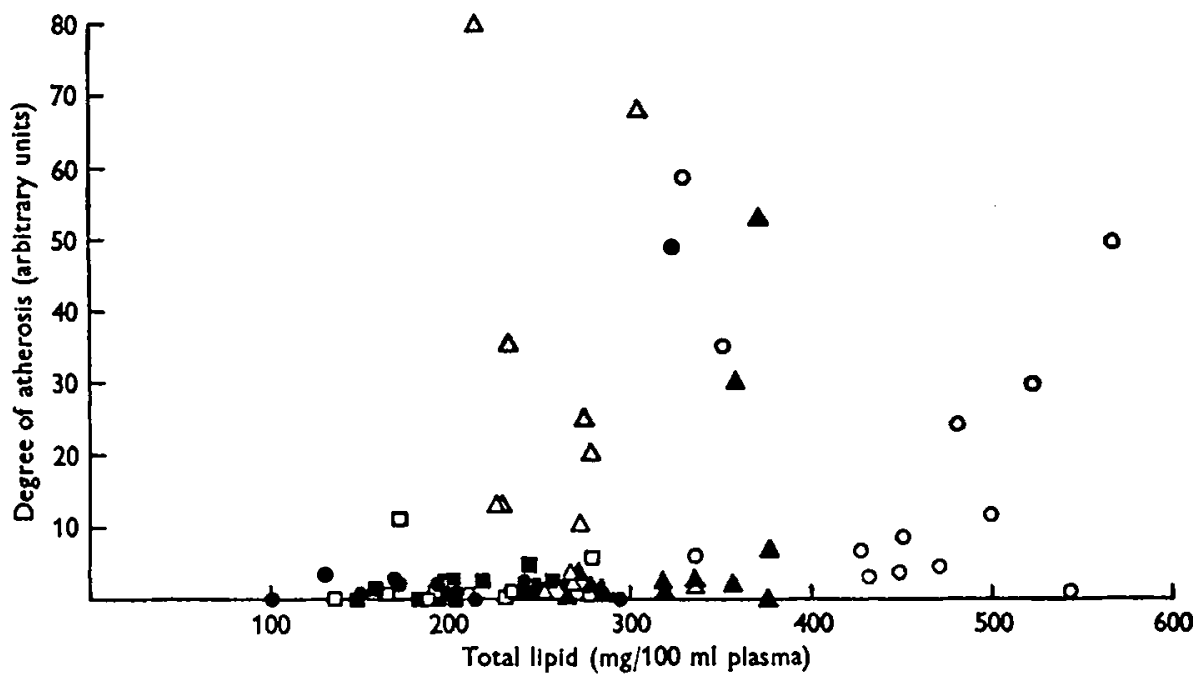

Fig. 2. Relationship between degree of atherosis (see p. 438) and total plasma lipid levels of individual rabbits (Expt 2). $\bullet$, group I ( $20 \%$ maize-oil diet); 0, group 2 ( $20 \%$ butterfat diet); $\Delta$, group 3 (10\% maize-oil, 10\% butterfat diet); $\Delta$, group 4 (low-fat, high-starch diet); $\square$, group 5 (10\% maize-oil, starch diet); $\bullet$ group 6 (commercial diet).

The results presented in Tables 2 and 3 show quite clearly that there was no direct relationship between the degree of aortic atherosis and the level of total cholesterol in the plasma of the rabbits in Expt 2. However, it seemed possible that a more justifiable comparison might be obtained if the two distinct forms of plasma cholesterol were considered separately. In Figs. 3 and 4 the levels of free and esterified cholesterol in the plasma of the individual rabbits in Expt 2 are plotted against the degrees of aortic atherosis. In neither is the relationship very striking, although it would seem that a degree of atherosis greater than 15 arbitrary units rarely occurred when the levels of free or esterified cholesterol were less than about $30 \mathrm{mg} / \mathrm{I} 00 \mathrm{ml}$ plasma. On the other hand, high levels of both free and esterified cholesterol in the plasma were frequently associated with very low degrees of aortic atherosis. The absence of any simple correlation between the degree of atheromatous degeneration of the aorta and blood cholesterol levels in the rabbits of Expt 2 is in agreement with the findings of Funch, Kristensen \& Dam (1962) also with rabbits given diets containing no added cholesterol. Funch et al. (1962) observed high levels of serum cholesterol and severe atherosis in the thoracic aortas of rabbits given for 38 weeks a diet containing $20 \%$ butterfat. Replacement of $40 \%$ of the butterfat by maize oil did not change the serum cholesterol levels but reduced by a factor of 5 the degree of atherosis in the thoracic aorta. With animals given diets supplemented with cholesterol, however, various investigators have reported striking correlations between blood cholesterol levels and degrees of atheromatous degeneration of the aorta. For instance, Cuth- 
bertson, Elcoate, Ireland, Mills \& Shearley (1959) found a linear relationship between serum cholesterol level and the degree of aortic athcrosis in groups of rats given diets containing $2 \%$ cholesterol. Gottenbos \& Thomasson (196I) observed that the degree of aortic atherosis increased with serum cholesterol levels in groups of rabbits given diets containing $0.04,0.08$ or $0.16 \%$ cholesterol. Nevertheless, Gottenbos \& Thomasson (196I) did note that the serum cholesterol levels of rabbits given for 52 weeks a diet containing coconut oil but no added cholesterol were higher, but the

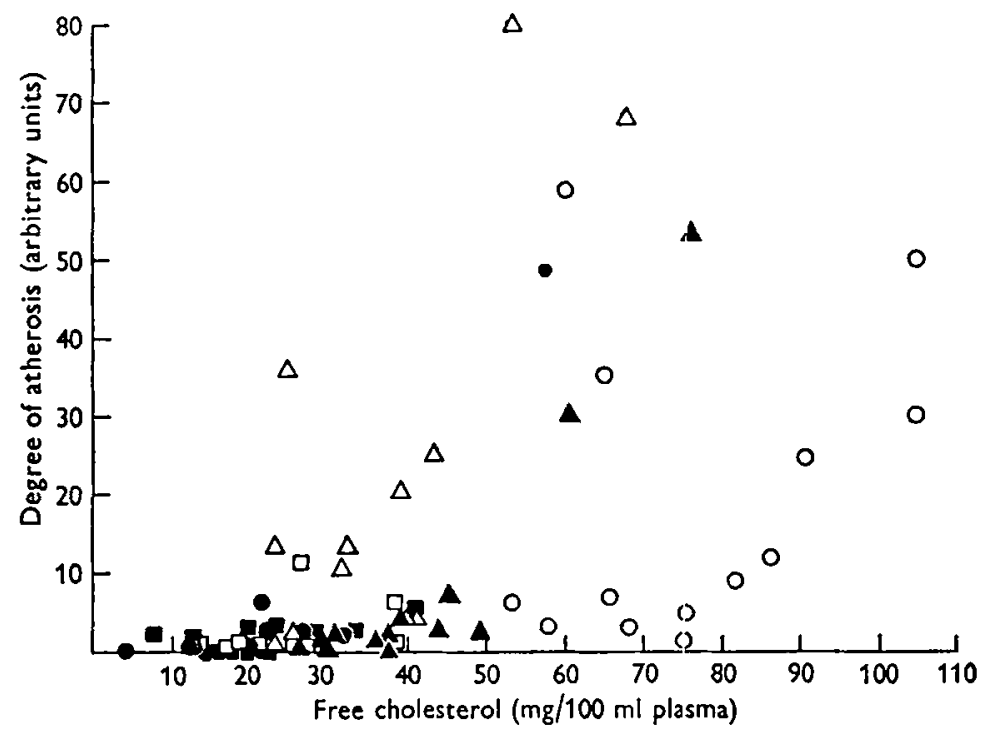

Fig. 3. Relationship between degree of atherosis (see p. 438) and plasma free cholesterol levels of individual rabbits (Expt 2). For explanation of symbols, see legend to Fig. 2.

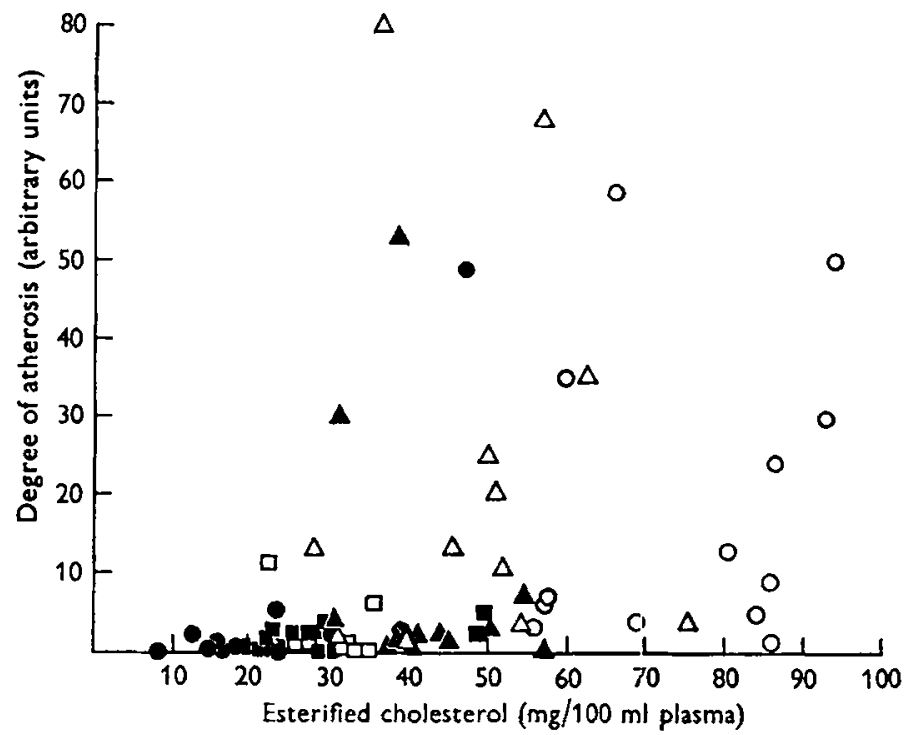

Fig. 4. Relationship between degree of atherosis (see p. 438) and plasma esterified cholesterol levels of individual rabbits (Expt 2). For explanation of symbols, see legend to Fig. 2. 
degree of aortic atherosis was lower, than for rabbits given for a similar period a diet containing $0.08 \%$ cholesterol but no coconut oil.

Triglyceride. The possibility of there being a relationship between the level of blood triglyceride and cardiovascular disease in man has only recently received attention for the simple reason that direct methods suitable for the routine analysis of blood triglycerides were not available until a few years ago (Van Handel \& Zilversmit, 1957; Carlson \& Wadström, 1959). Since then, serum triglyceride levels in patients with myocardial infarction have been studied by Albrink \& Man (1959), Carlson (1960), Antonis \& Bersohn (1960), Schrade, Böhle \& Biegler (1960), Schrade, Biegler \& Böhle (196r) and Albrink, Meigs \& Man (196r). The results of these studies have been reviewed by Albrink ( 1962 ) who concluded that coronary heart disease in man is accompanied more frequently by elevated levels of triglyceride than by elevated levels of cholesterol in the blood. It has been shown that a low-fat, high-carbohydrate diet in man is associated with much higher levels of plasma triglyceride than is a diet in which part of the dietary carbohydrate has been replaced by an isocaloric amount of fat (Ahrens, Hirsch, Insull \& Peterson, 1958; Kinsell, 1963).

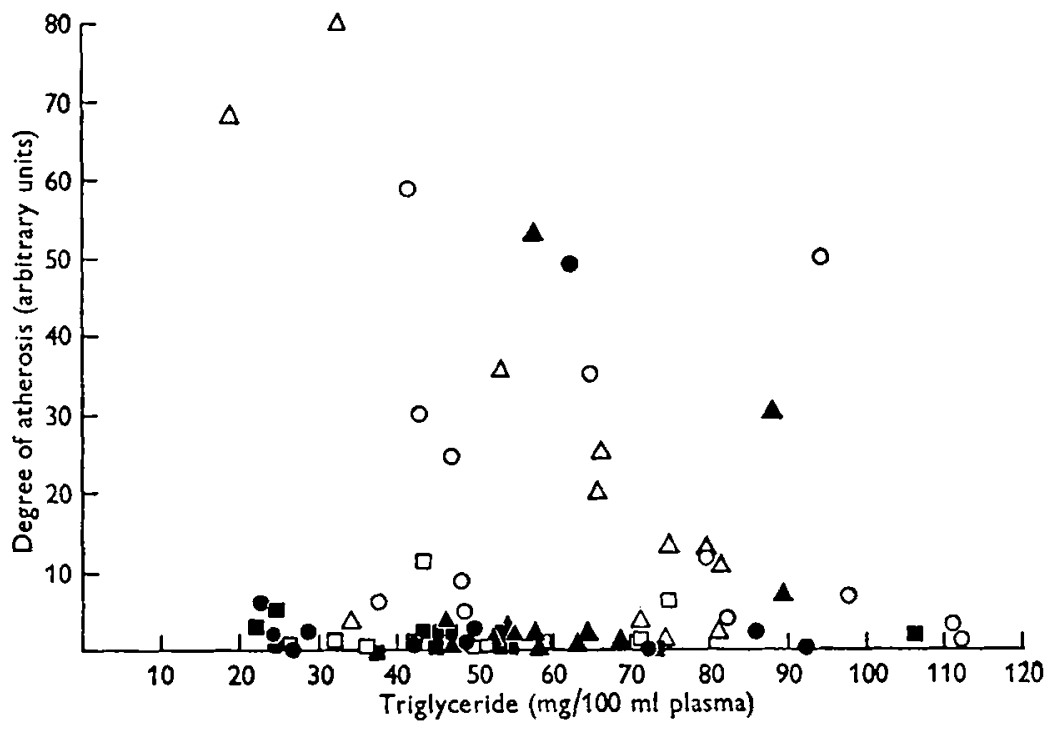

Fig. 5. Relationship between degree of atherosis (see p. 438) and plasma triglyceride levels of individual rabbits (Expt 2). For explanation of symbols, see legend to Fig. 2.

Moore \& Kon (1963) and Moore \& Williams (1964) reported that rabbits given a low-fat, high-carbohydrate diet developed severe aortic atherosis but only a moderate degree of hypercholesterolaemia. In view of the findings with man, therefore, it seemed tempting to speculate that elevated levels of triglyceride would be found in the plasma of these animals (group 5, Expt I and group 4, Expt 2). However, subsequent analysis (Tables I and 2) showed that it was not so. That there was no simple relationship between the degree of atherosis and plasma triglyceride levels in the rabbits of Expt 2 is shown quite clearly in Fig. 5. If the results presented in Fig. 5 can be said 
to conform to any pattern at all, then it would seem that there is a vague tendency for aortic atherosis to be most severe in those rabbits with intermediate levels of triglyceride in the plasma. The findings of Wigand (1959) and Gottenbos \& Thomasson (1961) also indicated that the degree of atheromatous degeneration of the aorta was poorly correlated with the level of triglyceride in the plasma of experimental rabbits.

Unesterified fatty acids. There would appear to be no correlation between the level of unesterified fatty acids in the blood and cardiovascular disease in man since Schrade et al. (1960) and Schrade et al. (1961) found that the levels of unesterified fatty acids in the serum of male patients with atherosclerosis were little different from the levels in the serum of a control group of normal male: subjects.

The results for the individual animals in Expt 2 are not considered in detail since it is evident from Tables 2 and 3 that there was no relationship between the levels of unesterified fatty acids in the plasma and the degree of aortic atherosis. For instance, the lowest levels of unesterified fatty acids were found in the plasma of the rabbits in groups 4 and $5(10.2$ and $10.7 \mathrm{mg} / 100 \mathrm{ml}$ respectively), yet the highest degree of aortic atherosis was observed in the rabbits of group 4 and the lowest in the rabbits of group 5 .

Phospholipid:cholesterol ratios. Ahrens \& Kunkel (1949) produced evidence in favour of the existence of a relationship between the fixation of lipid in the intima and a decreased phospholipid: cholesterol ratio in the serum. The following year, Morrison, Gonzalez \& Wolfson (1950) and Gertler, Garn \& Lerman (1950) reported that the phospholipid:cholesterol ratio in the serum of norma.. persons was substantially higher than in the serum of patients with coronary atherosclerosis. Similar observations were made subsequently by Steiner, Kendall \& Mathers (1952) and Oliver \& Boyd (1953). It was of considerable importance to discover whether this relationship between cardiovascular disease and a lowered phospholipid:cholesterol ratio in the blood represented any real advance in the search for some measurable abnormality in blood composition that could be usefully employed to diagnose atherosclerosis in its early stages. This question was taken up by Jackson \& Wilkinson (I952) who examined the composition of the plasma lipids in 102 normal individuals and in I 40 patients suffering from a variety of diseases including essential familial hypercholesterolaemia, hypothyroidism and coronary artery clisease. A highly significant correlation was found between the concentration of phospholipid and free cholesterol in the 242 plasma samples. This relationship could be represented by the equation $\log y=0.648 \log x+1 \cdot 190$, where $y=$ phospholipid concentration and $x=$ free cholesterol concentration in $\mathrm{mg} / 100 \mathrm{ml}$ plasma. No such relationship existed between phospholipid and total cholesterol. When the free cholesterol concentration was plotted against the phospholipid: free cholesterol ratio, a curve was obtained showing that an increase in the free cholesterol concentration was accompanied by a progressive decrease in the phospholipid:free cholesterol ratio until the latter value approached $2 \cdot 00$, after which it remained constant. Jackson \& Wilkinson (1952) point out that this limiting phospholipid:free cholesterol ratio (by weight) corresponds approximately to a $\mathbf{I}: \mathbf{I}$ molar ratio. Since the free cholesterol forms a relatively constant proportion of the total cholesterol in human plasma, Jackson \& Wilkinson $(1952)$ concluded that 'the average hypercholesterolaemia in such diseases as coronary 
sclerosis...can in itself explain the lower average phospholipid to total cholesterol ratios which have been reported'. Nevertheless, Steiner et al. (1952) found that the phospholipid: cholesterol ratio in the serum of a group of patients with coronary disease was considerably lower than that in the serum of a control group of normal individuals in spite of the fact that the total concentration of cholesterol in the serum of both of these particular groups was exactly the same.

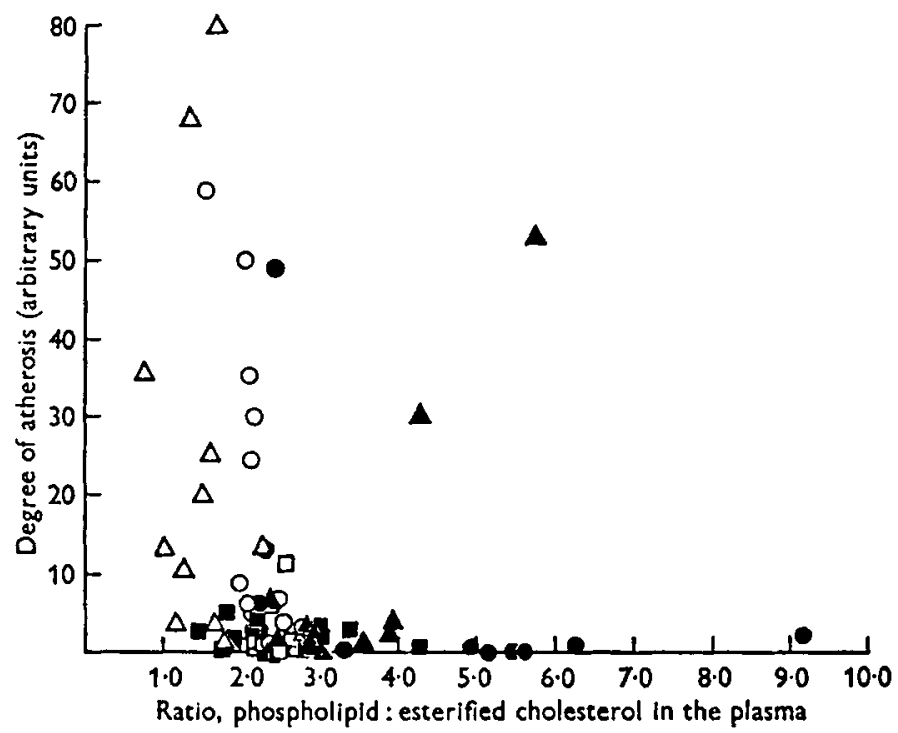

Fig. 6. Relationship between degree of atherosis (see p. 438) and the phospholipid : esterified cholesterol ratio in the plasma of individual rabbits (Expt 2). For explanation of symbols, see legend to Fig. 2.

Although Wigand (1959) noted a marked correlation between the frequency and severity of the aortic lesions and the phospholipid:total cholesterol ratio in the serum of experimental rabbits it would seem more appropriate, particularly in view of the findings of Jackson \& Wilkinson (1952), to examine whether the degree of aortic atherosis in the rabbits of Expt 2 was correlated with the phospholipid:esterified cholesterol ratio or with the phospholipid:free cholesterol ratio in the plasma. As may be seen from Fig. 6, there was no obvious correlation between the degree of atherosis and the phospholipid: esterified cholesterol ratio. On the other hand, there was a significant correlation between the degree of aortic atherosis and the phospholipid: free cholesterol ratio in the plasma (Fig. 7). The relationship between the degree of aortic atherosis $(D)$ and the phospholipid: free cholesterol ratio $(R)$ in the plasma may be described by a curve of the form

$$
D=A(R-K)^{b},
$$

which corresponds to the linear relationship

$$
\log D=\log A+b \log (R-K),
$$


where $A$ and $b$ are constants and $K$ represents the lower limit approached by the ratio $R$. Such a curve fitted to the combined values from the six groups of rabbits is shown in Fig. 7 and has the equation

$$
D=23 \cdot 80(R-0.90)^{-3 \cdot 416} \text {. }
$$

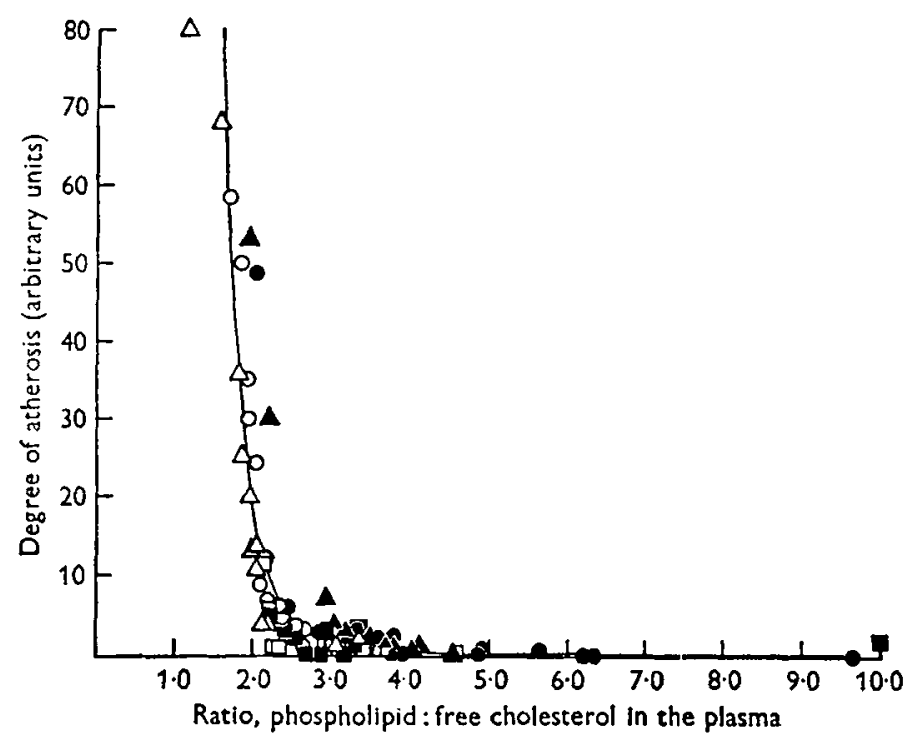

Fig. 7. Relationship between degree of atherosis (see p. 438) and the phospholipid: free cholesterol ratio in the plasma of individual rabbits (Expt 2). For explanation of symbols, see legend to Fig. 2.

In fitting the curve, zero values for the degree of aortic atherosis $(D)$ were omitted and the value of the limit $K$ was estimated by iteration. 'The resulting regression was highly significant $(P<0.001)$. However, estimates of the parameters of the curve differ significantly for the various diet groups and hence: equation 3 can be regarded as only an approximate description of the relationship between $D$ and $R$ for any particular dietary treatment. Thus it would seem that, under the conditions of Expt 2, little or no atherosis occurred in the rabbits, irrespective of dietary treatment, when the phospholipid: free cholesterol ratio (by weight) in the plasma was greater than $2 \cdot 0$ or thereabouts. When the ratio fell below this value tie degree of aortic atherosis increased markedly. In spite of the fact that the severity of the lesions in the rabbits of Expt I was graded only semi-quantitatively, it would seem that a similar relationship existed between the degree of aortic atherosis and the phospholipid: free cholesterol ratio in the plasma of the rabbits in this experiment (Fig. 8). On the assumption that lecithin $\left(M_{780}\right)$ is the major phospholipid of rabbit plasma, a phospholipid: free cholesterol ratio (by weight) of $2 \cdot 0$ corresponds approximately to a I : I molar ratio (cf. Jackson \& Wilkinson, 1952). In the experiments described here it is clear that a decreased phospholipid:free cholesterol ratio in the plasma of the rabbits was not merely a function of an increased cholesterol level. This is shown particularly well by Expt 2 when the rabbits of group 3 are compared with those of group 4. If the concentrations of the various lipids in the plasma of the rabbits of group 6 (given the 
commercial diet) are accepted as being normal, then the degree of hypercholesterolaemia observed for the rabbits of group 3 (given the $10 \%$ maize-oil- $10 \%$ butterfat diet) was exactly the same as that observed for the rabbits of group 4 (given the highstarch diet). Nevertheless, this degree of hypercholesterolaemia was associated with an increased incidence of aortic atherosis in the rabbits of group 4 only when the rise in plasma cholesterol was not accompanied by a concomitant rise in plasma phospholipid. This finding is similar to that reported by other investigators in this field under quite different experimental conditions. Ladd, Kellner \& Correll (1949)

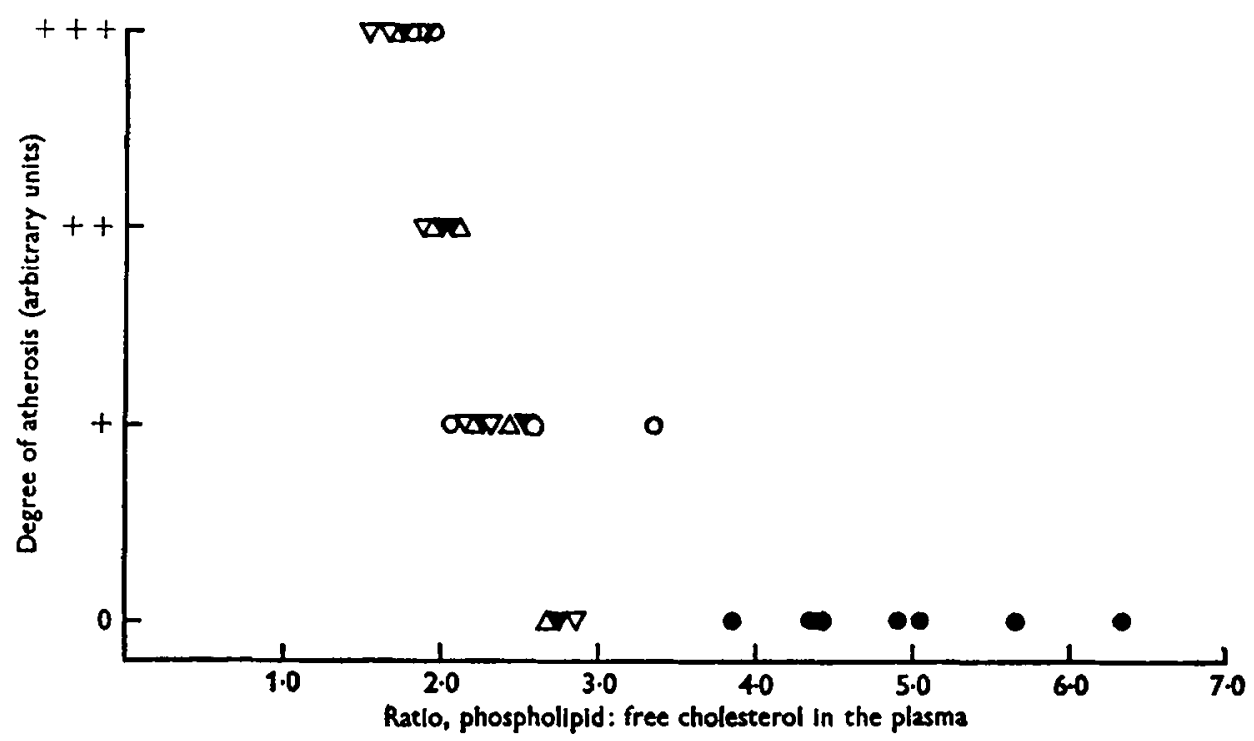

Fig. 8. Relationship between degree of atherosis (see p. 438) and the phospholipid:free cholesterol ratio in the plasma of individual rabbits (Expt 1 ). $\bullet$, group I (10\% maize-oil diet); $\nabla$, group 2 ( $24 \%$ butter diet); 0 , group 3 (20\% butterfat diet); $\nabla$, group 4 ( $20 \%$ hydrogenated coconut-oil diet); $\Delta$, group 5 (high-starch diet).

observed higher levels of plasma cholesterol but less severe atherosis in rabbits given a normal diet and intravenous injections of Tween 80 (polyoxyethylene sorbitan mono-oleate) than in rabbits given cholesterol in the diet but no intravenous injections of Tween 8o. In the animals receiving Tween 80 intravenously but no dietary cholesterol the levels of phospholipid in the plasma were as high as or higher than the corresponding cholesterol levels, whereas in the animals receiving dietary cholesterol but no Tween 80 intravenously, the levels of phospholipid in the plasma were only about half the corresponding cholesterol levels. Ladd et al. (1949) found also that the intravenous injection of Tween 80 into rabbits given a diet containing cholesterol increased the level of phospholipid in the plasma and reduced the incidence and severity of atherosis in spite of a sustained hypercholesterolaemia. Duff \& McMillan (1949) observed that the severity of atheromatous lesions in rabbits given a diet containing cholesterol and rendered diabetic with alloxan was much less than in normal rabbits receiving the same diet. The serum cholesterol levels were the same in both groups although a greater degree of visible lipaemia was noticed in the diabetic 
rabbits. Duff \& Payne (1950) conducted a more detailed study of the serum lipids and found that in the alloxan-diabetic rabbits given dietary cholesterol there were much higher levels of phospholipid and neutral fat than in the normal rabbits receiving dietary cholesterol. They considered that the increased levels of phospholipid, rather than the increased levels of neutral lipid, were responsible for the reduced incidence of atherosis in the diabetic rabbits given dietary cholesterol. Both Ladd et al. (1949) and Duff \& Payne (1950) infer that increased levels of phospholipid in the blood may modify or even prevent the development of experimental atherosis.

In conclusion, therefore, it would seem that, under the conditions of Expts I and 2, the degree of atheromatous degeneration in the aortas of the rabbits was associated with elevated plasma cholesterol levels only when the levels of phospholipid in the plasma were insufficient to maintain the molar ratio phospholipid:free cholesterol above a value of about $\mathrm{x} \cdot \mathrm{O}$. It is conceivable that equimolar proportions of phospholipid and free cholesterol may be essential for the maintenance of a stable lipoprotein system in the plasma.

\section{SUMMARY}

I. In Expt $\mathrm{r}$, groups of male rabbits (six to eight per group) were given ad lib. for a period of $3^{\text {I }}$ weeks a diet consisting of 80 parts of a basal ration to which were added: for group I, 20 parts of maize oil ; for group 2, 24 parts of butter; for group 3, 20 parts of butterfat; for group 4, 20 parts of hydrogenated coconut oil; and for group 5, I part of maize oil and 42 parts of wheat starch. In Expt 2 groups of male rabbits (ten to thirteen per group) were given ad lib. for a period of 38 weeks a diet consisting of 80 parts of the basal ration to which were added: for group I, 20 parts of maize oil; for group 2, 20 parts of butterfat; for group 3, Io parts of maize oil and Io parts of butterfat; for group 4, 0.47 parts of maize oil and 43 parts of wheat starch; and for group 5 , I0.2 parts of maize oil and $21 \cdot 6$ parts of wheat starch. The animals in group 6 were given an ordinary commercial rabbit diet.

2. At the end of the experiment, a large sample of blood was taken from each rabbit. The animals were then killed and the degree of atheromatous degeneration was determined after the aortas had been stained with Sudan IV. The samples of plasma were analysed for total lipid, free and esterified cholesterol, triglyceride, phospholipid and unesterified fatty acids.

3. The levels of the various lipids in the plasma of the rabbits given the $20 \%$ maizeoil diet were very similar to the corresponding levels for the rabbits given the commercial diet. The experimental diets containing $24 \%$ butter, $20 \%$ butterfat or $20 \%$ hydrogenated coconut oil gave rise to elevated levels of total lipid, free and esterified cholesterol and phospholipid in the plasma. In addition, the diet containing $20 \%$ hydrogenated coconut oil resulted in raised levels of triglyceride and unesterified fatty acids in the plasma. A moderately elevated level of plasma cholesterol was observed in the rabbits given the low-fat, high-starch diet but the phospholipid level in the plasma of this group was no higher than in the plasma of the group given the $20 \%$ maize-oil diet. The degree of hypercholesterolaemia found for the rabbits given the low-fat, high-starch diet was the same as that found for the rabbits given the diet 
containing $10 \%$ maize oil and $10 \%$ butterfat. However, the level of phospholipid in the plasma of the rabbits given the $10 \%$ maize-oil-10\% butterfat diet was about twice the corresponding level for the rabbits given the low-fat, high-starch diet.

4. The results obtained for the individual rabbits of Expt 2 were examined to determine the extent of the relationship between the concentration of the various lipid components in the plasma and the degree of aortic atherosis. The most striking correlation was that between the phospholipid:free cholesterol ratio in the plasma and the degree of aortic atherosis. Irrespective of dietary treatment or absolute level of plasma cholesterol, it appeared that aortic atherosis was severe when the phospholipid: free cholesterol ratio (molar) in the plasma was less than about $\mathrm{I} \cdot \mathrm{O}$. When this molar ratio was greater than $\mathrm{I} \cdot \mathrm{O}$ little or no atherosis was observed.

The authors gratefully acknowledge the encouragement and advice given by Dr S. K. Kon and thank Mr D. R. Westgarth for statistical analysis of the results and Miss J. Carrinci, Mr E. V. Ruby and Mr G. Quelch for skilled technical assistance. This study was supported by a grant from the Butter Information Council.

\section{REFERENCES}

Ahrens, E. H. Jr., Hirsch, J., Insull, W. Jr. \& Peterson, M. L. (1958). In Chemistry of Lipids as Related to Atherosclerosis, p. 222. [I. H. Page, editor.] Springfield, Ill.: C. C. Thomas.

Ahrens, E. H. \& Kunkel, H. G. (1949). F. $\operatorname{exp.~Med.~90,~} 409$.

Albrink, M. J. (1962). Arch. intern. Med. 109, 145.

Albrink, M. J. \& Man, E. B. (r959). Arch. intern. Med. ro3, 4.

Albrink, M. J., Meigs, J. W. \& Man, E. B. (1961). Amer. F. Med. 3r, 4.

Antonis, A. \& Bersohn, I. (1960). Lancet, i, 998.

Barron, E. J. \& Hanahan, D. J. (1958). F. biol. Chem. 231, 493.

Carlson, L. A. (1960). Acta med. scand. 167, 399.

Carlson, L. A. \& Wadström, L. B. (1959). Clin. chim. Acta, 4, 197.

Cuthbertson, W. F. J., Elcoate, P. V., Ireland, D. M., Mills, D. C. B. \& Shearley, P. (r959). Brit. F. Nutr. r3, 227.

Duff, G. L. \& McMillan, G. C. (1949). F. exp. Med. 89, 6r I .

Duff, G. L. \& Payne, T. P. B. (1950). F. $\operatorname{exp.~Med.~92,~} 299$.

Duncan, D. B. (1955). Biometrics, II, I.

Folch, J., Lees, M. \& Stanley, G. H. S. (1957). Y. biol. Chem. 226, 497.

Funch, J. P., Kristensen, G. \& Dam, H. (1962). Brit. J. Nutr. 16, 497.

Funch, J. P., Krogh, B. \& Dam, H. (1960). Brit. F. Nutr. 14, 355.

Gertler, M. M., Garn, S. M. \& Lerman, J. (1950). Circulation, 2, 205.

Gottenbos, J. J. \& Thomasson, H. J. (196r). Colloq. int. Cent. nat. Rech. sci. no. 99, p. $22 \mathrm{I}$.

Hirsch, E. F. \& Weinhouse, S. (1943). Physiol. Rev. 23, 185.

Jackson, R. S. \& Wilkinson, C. F. (1952). Ann. intern. Med. 37, I 162.

Kinsell, L. W. (1963). In Progress in the Chemistry of Fats and Other Lipids. Vol. 6, p. 138. [R. T. Holman, W. O. Lundberg, and T. Malkin, editors.] Oxford: Pergamon Press.

Kramer, Y. K. (1956). Biometrics, 12, 307.

Kritchevsky, D. (1958). Cholesterol, p. 143. New York: John Wiley and Sons, Inc.

Ladd, A. T., Kellner, A. \& Correll, J. W. (1949). Fed. Proc. 8, 360.

Lande, K. E. \& Sperry, W. M. (1936). Arch. Path. (Lab. Med.), 22, 301.

Lis, E. W., Tinoco, J. \& Okey, R. (196r). Analyt. Biochem. 2, 100.

Mangold, H. K. (196r). 7. Amer. Oil Chem. Soc. 38, 708.

Moore, J. H. (1962). F. Dairy Res. 29, 141.

Moore, J. H. \& Doran, B. M. (1962). Biochem. F. 84, 506.

Moore, J. H. \& Kon, S. K. (1963). Chem. Eீ Ind. p. 165.

Moore, J. H. \& Williams, D. L. (1963). Canad. Y. Biochem. Physiol. 4r, I82 r.

Moore, J. H. \& Williams, D. L. (1964). Brit. F. Nutr. 18, 253.

Morrison, L. M., Gonzalez, P. \& Wolfson, E. (1950). Circulation, 2, 472. 
Nelson, G. J. \& Freeman, N. K. (1959). F. biol. Chem. 234, 1375.

Oliver, M. F. \& Boyd, G. S. (1953). Brit. Heart Y. $15,387$.

Schrade, W., Biegler, R. \& Böhle, E. (196I). F. Atherosclerosis Res. 1, 47.

Schrade, W., Böhle, E. \& Biegler, R. (1960). Lancet, ii, 1409.

Steiner, A., Kendall, F. E. \& Mathers, J. A. L. (I952). Circulation, 5, 605.

Van Handel, E. \& Zilversmit, D. B. (1957). F. Lab. clin. Med. 50, I 52.

Wigand, G. (1959). Acta med. scand. 166, Suppl. no. 351.

Wittcoff, H. (195I). The Phosphatides, p. I7I. New York: Reinhold Publishing Corp. 